\title{
Words: Um Jogo para o Auxílio à Aprendizagem de Inglês como Segundo Idioma
}

\author{
Claudio Victor Alves, Pasqueline Dantas Scaico ${ }^{1}$ \\ ${ }^{1}$ Departamento de Ciências Exatas \\ Universidade Federal da Paraíba - Rio Tinto, PB
}

\begin{abstract}
This paper presents Words, a game that has been designed to support students in their process of learning English as a second language. Words is based on two models of game design, the GameFlow and MDA (Mechanics, Dynamics, and Aesthetics) to achieve a certain level of fun during the game experience and, consequently, students' engagement. We are currently evaluating Words according to pedagogical lenses through teachers of English and beginners in this language.
\end{abstract}

Resumo. Este artigo apresenta o Words, um jogo que vem sendo desenvolvido para auxiliar a aprendizagem de inglês como segundo idioma. O Words se baseia em dois modelos de game design, o GameFlow e o MDA (Mechanics, Dynamics, and Aesthetics), com o intuito de tornar a experiência de jogo divertida e, consequentemente, engajadora para o estudante. Atualmente, o design instrucional do Words está sendo avaliado com professores de inglês e iniciantes no idioma.

\section{Introdução}

Existe um desafio presente na indústria de desenvolvimento de jogos sérios que se apresenta na forma de como alcançar com jogos educativos o nível de engajamento dos comerciais (SAVI e ULBRICHT, 2008). Em outras palavras, é muito difícil projetar um jogo que seja divertido ao passo que seja um meio para que o jogador aprenda. Um dos aspectos que desafiam o design deste tipo de recurso educacional é projetar uma experiência pedagógica capaz de fazer o estudante alcançar o estado de flow (PAIVA e TORI, 2017). O jogo Words está sendo desenvolvido com o propósito de apresentar uma experiência de aventura e mistério ao jogador, bem como explorar suas habilidades no idioma inglês através da resolução de enigmas. Ele combina elementos de game design que agregam diversão à interação, tais como: combate, exploração, mistério, recompensas e feedback. Durante este artigo o estudante será referenciado como jogador. As ações que ocorrem no Words foram projetadas para integrar situações comuns a jogos de entretenimento à dimensão instrucional, tornando-o, assim, mais próximo de uma experiência de gameplay. Este artigo está estruturado da seguinte forma: Na Seção 2 não narrados desafios projetados no Words. Na Seção 3, discute-se elementos de game design do Words, ao passo que lança algumas reflexões iniciais sobre o seu potencial como recurso para aprendizagem. 


\section{O jogo Words}

Words é um jogo 2D, com estilo artístico monocromático em escalas de preto e branco inspirado no jogo Limbo ${ }^{1}$. Possui mecânicas, enigmas e desafios baseados no jogo Typoman ${ }^{2}$. Ele se fundamenta em ações de "arrastar e soltar", muito presentes em jogos para plataformas móveis. A sua mecânica principal foi desenvolvida sob o pensamento construtivista, em que a vivência de situações e a realização de atividades lúdicas interativas propiciam a construção do saber (PIAGET, 1980).

\subsection{Mecânica dos Desafios no Words e Suas Implicações}

A definição de mecânica é o oposto de algo orgânico. Logo, tudo é direcionado, linear e com ações programadas, que estão à espera de um gatilho que as acione. Com isso em mente, os desafios do Words atendem a princípios em que o jogador desencadeia alterações no mundo do jogo para seguir um caminho, a partir do seu conhecimento sobre inglês. Os desafios são obstáculos a serem superados. A estrutura deles é dada por: 1 . blocos de letras espalhadas no cenário; 2 . um campo de preenchimento, no qual os blocos de letras são encaixados; 3 . um pequeno led e 4 . um botão de dica (vide legenda na Figura 1 para identificar os quatro elementos).

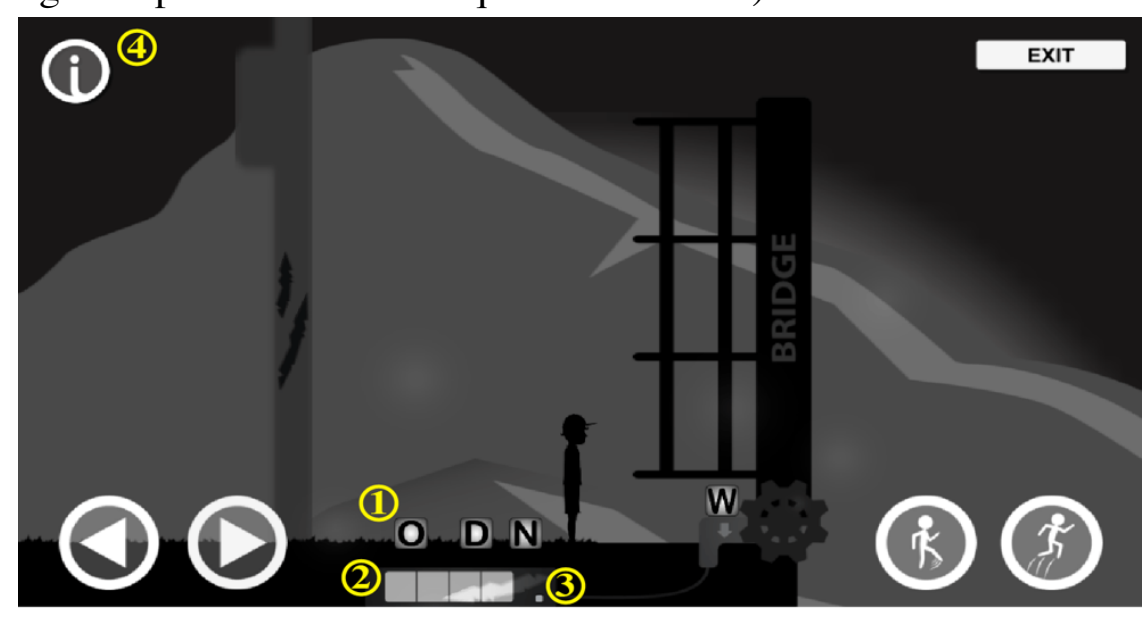

Figura 1. Exemplo de desafio - Legenda: (1) bloco de letras, (2) campo de preenchimento, (3) led e (4) botão de dica

Os blocos de letras são interativos e representam os principais elementos para a resolução de um desafio. O campo de preenchimento espera uma ordem exata de encaixe dos blocos de letras, para que nele seja formada uma palavra específica em inglês que desencadeia uma ação e libera o caminho para o jogador. Observe na Figura 1 a existência na interface de um pequeno led (representado pelo número 3). Ele é o elemento que provê feedback para o jogador. Inicialmente, o led está apagado. A conclusão correta do desafio o acende, indicando para o jogador que ele acertou. Um botão de dica pode ser acionado pelo jogador, no qual uma frase em português oferece pistas para a resolução do desafio. O desafio estimula o jogador a explorar a interface e a se perguntar: "O que devo fazer aqui para que algo aconteça?". O contexto do jogo

\footnotetext{
${ }^{1}$ Disponível em: https://playdead.com/games/limbo/ Acesso em 29 de abril de 2020

2 Disponível em: http://www.typoman.net/ Acesso em 29 de abril de 2020
} 
leva o jogador a pensar sobre situações que ele reconhece. Imagine-se como jogador do Words: em um dos desafios, você está percorrendo um caminho e se depara com uma ponte levadiça próximo a um penhasco. Você precisa passar para o outro lado e a ponte é o único meio para atravessá-lo. Você observa no mecanismo da ponte que existe uma seta apontando para baixo e um campo com quatro espaços vazios. Há também quatro letras espalhadas na tela: D, W, O, N. Em algum momento, você entende como resolver os desafios: que basta formar uma palavra com as letras que estão a sua disposição. Observando a situação e o ambiente, você pensa sobre o que fazer com as letras. Se formar a palavra DOWN, imediatamente, o led acende e a ponte levadiça começa a descer tornando possível a sua passagem pelo penhasco (vide Figura 2. Note que a cor do led está mais acentuada).

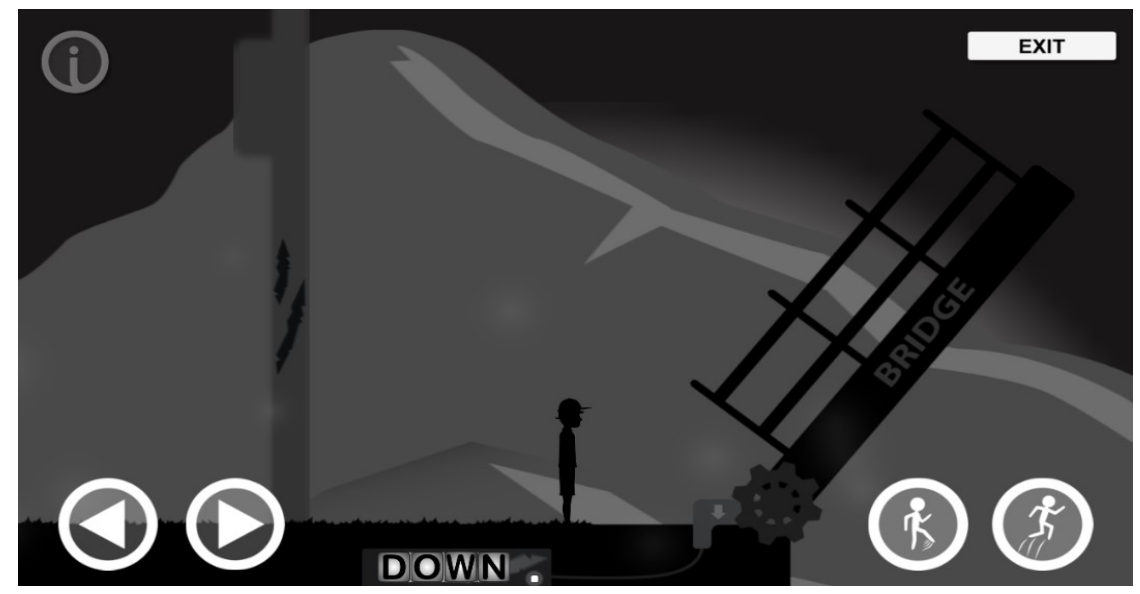

Figura 2. Conclusão de Desafio

Outra situação que pode ocorrer é você se aproximar da frustração por não conseguir decifrar o desafio. Ao acessar o botão Dica, a frase "Não há como passar com essa ponte levantada! Vamos baixá-la!" é exibida (Figura 3). A palavra-chave da frase tem a ver como baixar. Ao fazer esta associação, você é auxiliado a pensar em um termo em inglês que esteja relacionado à solução do desafio: a palavra DOWN.

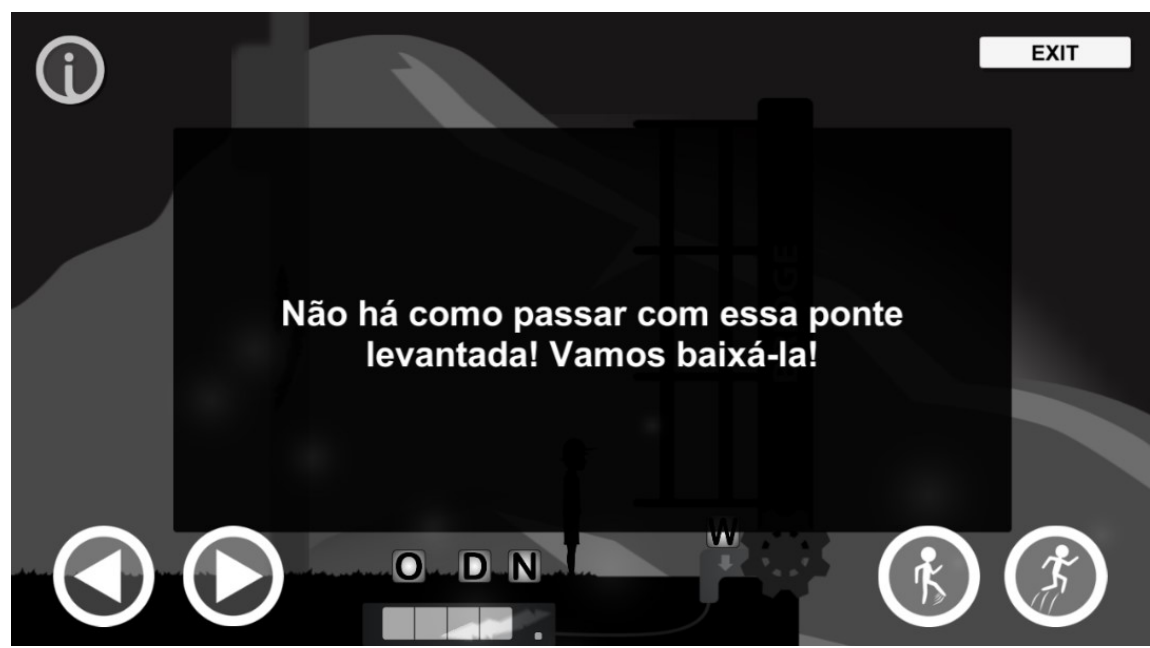

Figura 3. Exemplo de dica 
Cada desafio possui um contexto, que define a palavra a ser formada para a conclusão do desafio. Entre um desafio e outro o jogador é apresentado a elementos, como exploração e combate, tais como, enfrentar um cão das sombras; passar de um campo para uma fábrica ou entrar em uma sala com máquinas, dentre outros.

\subsection{Categorização dos Desafios}

Além da mecânica geral dos desafios, eles são divididos em duas categorias principais: desafios simples e desafios compostos. Os desafios simples possuem apenas a mecânica genérica, onde uma palavra desencadeia uma ação. Os desafios compostos potencializam a dificuldade e contam com até dois campos de preenchimento. Assim, são necessárias duas palavras relacionadas para solucionar o desafio. Vejamos um exemplo: o jogador está em uma sala, diante de um elevador desativado e uma fornalha. Cada um contém um campo de preenchimento. Na fornalha, a palavra COLD estava formada no campo de preenchimento. O jogador deve remover a palavra COLD e montar a palavra FIRE na fornalha e depois ON no elevador para que energia seja gerada e o elevador ativado (vide Figura 4). Caso ele monte apenas uma das palavras na ordem incorreta, nenhuma ação é desencadeada.

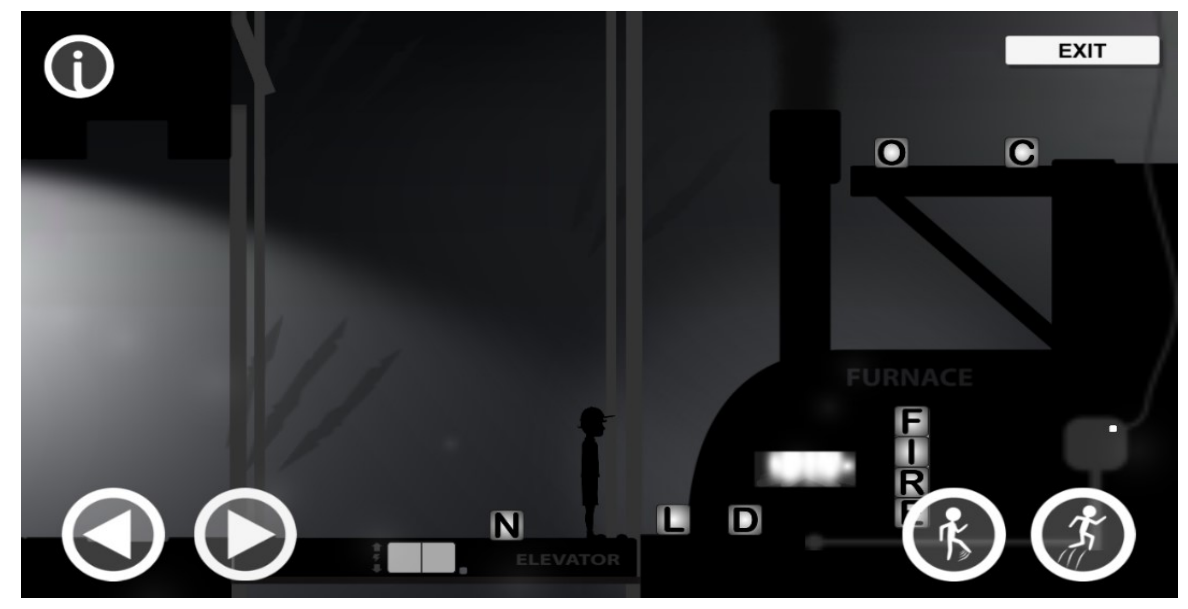

Figura 4. Ilustração de Desafio Composto

\section{O game design do Words e a imersão do jogador}

Words foi desenvolvido sob a aplicação de dois modelos de game design: o GameFlow e o MDA (Mechanics, Dynamics, and Aesthetics) (SWEETSER e WYETH, 2005) (HUNICKE et al, 2004), os quais visam alcançar o fator de diversão chamado Hard Fun, conforme o modelo Four Keys to Fun (4K2F) de Lazzaro (2004). No 4K2F, um agrupamento de mecânicas revela a existência de quatro tipos de jogador. O Words foi projetado para jogadores com perfil Hard Fun, jogam para demonstrar as habilidades que possuem. Seu gameplay proporciona desafios e domínio para que as habilidades de quem joga sejam provadas através de mecânicas contendo desafios com níveis progressivos de dificuldade; natureza variada de feedbacks e o envolvimento das emoções: frustração, fiero (senso de superação de obstáculos) e alívio.

O modelo GameFlow do Words se baseia na Teoria do Fluxo de Experiência (CSIKSZENTMIHALYI, 2008). Para alcançar a imersão do jogador, diversos elementos podem ser incorporados no design, alguns dos quais: possibilidade de 
conclusão das tarefas; objetivos claros; feedback imediato; sensação de controle sobre as ações e o senso de da alteração na passagem do tempo, dentre outros. Esses elementos estimulam que o jogador se desloque entre dois extremos: o da ansiedade e apatia, que se permutam em um fluxo contínuo e ininterrupto. Ao entrar neste ciclo, o jogador entra no estado de flow, no qual sua concentração no jogo é elevada. No Words, o GameFlow foi implementado para permitir a conclusão dos desafios, o que estimula que o jogador se concentre por entender que consegue fazê-lo. Os objetivos claros do Words, o feedback imediato e dicas, que requerem certo grau de interpretação, afastam o jogador do extremo da apatia. As mudanças ocasionadas pela realização dos desafios transmitem a sensação de controle. A curiosidade é mantida entre um desafio e outro através de obstáculos e mudanças no cenário, todos exibidos gradativamente para afastar o jogador do extremo da ansiedade. Segundo o esquema MDA, os elementos de Aesthetic (estética) se preocupam com a diversão, as emoções relacionadas, e em proporcionar senso de imersão do jogador. Words está sendo desenhado para provocar um senso de prazer, que é atingido pela possibilidade de progredir com a aventura e visualização das modificações do mundo do jogo após a conclusão de um desafio. $\mathrm{O}$ Words procura simular um mundo de faz-de-conta que promove fantasia e traz um enredo com mistério. Os obstáculos que aparecem no percurso do jogador o fazem pensar e descobrir aspectos novos a cada desafio, A autodescoberta é um elemento importante segundo o MDA. No Words, isto é alcançado porque o jogador pode avaliar o seu nível de conhecimento no idioma inglês.

O Words busca alcançar a imersão do jogador através de inúmeros elementos de game design. Ao adicionar um conteúdo, neste caso, vocabulário no idioma inglês, busca-se tornar a aprendizagem deste conteúdo uma consequência da ação de jogar. Criar experiências de gameplay semelhantes àquelas encontradas em jogos comerciais é possível. O Words mostra que este objetivo pode ser alcançado através da aplicação de critérios de imersão em fluxo e envolvimento de emoções. É uma linha de concepção de software educativo em que o aluno aprende brincando, é protagonista do seu aprendizado e realiza atividades lúdicas que estão contextualizada na narrativa do jogo. Ele está sendo desenvolvido com a game engine Unity. Levando em consideração que muitos estudantes possuem um smartphone com Android, o Words foi desenvolvido para esta plataforma, tomando a resolução $1280 \times 720$ como base, mas com responsividade para vários tamanhos de tela. Para jogar alguns desafios do Words, acesse: https://gamejolt.com/games/words/514369.

\section{Referências}

Csikszentmihalyi, M. Optimal experience: psychological studies of flow in consciousness, Cambridge, UK: Cambridge University Press, 1988.

Hunicke, R.; Leblanc, M.; Zubek, R. MDA: A Formal Approach to Game Design and Game Research. January 2004.

Paiva, Carlos A.; Tori, Romero. Jogos Digitais No Ensino: Processos Cognitivos, Benefícios E Desafios. Sbc - Proceedings of SBGames (2017).

Savi, Rafael; Ulbricht, Vania Ribas, Dra. Jogos Digitais Educacionais: Benefícios E Desafios. V. $6 \mathrm{~N}^{\circ} 2$, (2008).

Sweetser, P.; Wyeth, P. GameFlow: A Model for Evaluating Player Enjoyment in Games. ACM Computers in Entertainment, Vol. 3, No.3, July 2005. 